\title{
Chondrodysplasia Punctata: A Case Report of Fetal Warfarin Syndrome
}

\author{
Swachchhanda Songmen, ${ }^{1}$ Om Biju Panta, ${ }^{2}$ Sharma Paudel S, ${ }^{1}$ Ram Kumar Ghimire ${ }^{1}$ \\ 'Department of Radiology and Imaging, Tribhuvan University Teaching Hospital, Kathmandu, Nepal, \\ 2Department of Radiology and Imaging, Koshi Zonal Hospital, Morang, Nepal.
}

\section{ABSTRACT}

Chondrodysplasia punctata is abnormal calcification in the cartilage of developing bones and has been seen in association
with deranged vitamin $\mathrm{K}$ metabolism. Warfarin, an oral anticoagulant acting on vitamin $\mathrm{K}$ dependent clotting factors
is known to cause chondrodysplasia punctata. Despite the knowledge of the condition the management of patients
with prosthetic heart valves might require use of the drug for anticoagulation. Here, we present a case of a fetal
warfarin syndrome in a second born child of a 27 year lady under warfarin for prosthetic heart valve. The pregnancy
was complicated by polyhydramnios in third trimester and terminated at term by normal vaginal delivery. The baby
was well, except for facial dysmorphism in the form of depressed nasal bridge, narrow nares and suspected left
choanal atresia. Radiograph revealed stippled ephiphysis of vertebra, femora and humera supporting diagnosis of fetal
warfarin syndrome. The baby did not develop any perinatal complication and was discharged home.
Keywords: Chondrodysplasia punctata; fetal warfarin syndrome; vitamin K deficiency.
\end{abstract}

\section{INTRODUCTION}

Stippled epiphysis is seen in many acquired and inherited disorders as drug exposure (warfarin and phenytoin), metabolic disorders, trisomies $(18,21)$ and maternal illnesses. ${ }^{1}$ Despite its teratogenicity and classification as FDA class $X$ drug (absolute contraindication in pregnancy), warfarin use in prosthetic heart valve patients may be justified, however with risk of fetal warfarin syndrome (FWS). Here we present a case of fetal warfarin syndrome in anewborn to a mother under warfarin for prosthetic heart valve.

\section{CASE REPORT}

A female infant was born vaginally at 37 weeks of gestation to a 27-year-old, gravida 2, para 1 with no consanguinity history. Mother had rheumatic heart disease with severe MS, severe AS, moderate AR for several years. She underwent double valve replacement one year back and started on $5 \mathrm{mg} / 6 \mathrm{mg}$ alternate day warfarin sodium (coumadin) as anticoagulation prophylaxis with prothrombin time 30-35 seconds. She continued warfarin until 35 weeks of gestation until she visited our center for delivery when it was changed to enoxaparin.
Her first baby was healthy term male with normal delivery 4 years back. There is no past history of stillbirths. On second (current) pregnancy, she took regular iron \& calcium tablets but not folic acid. She had four ANC visits. Anomaly USG scan at another center was normal. She developed polyhydramnios in early third trimester.

The neonate had normal APGAR scores and no complications. Birth weight was $2.25 \mathrm{~kg}$. However, the newborn had depressed nasal bridge with deep groove between the alaenasi and nasal tip (Figure 1). Nasogastric tube could not be pushed more than $3 \mathrm{~cm}$ from external nares. ENT evaluation revealed stenosed nasal aperture. Infant tube number 07 size was negotiable with difficulty through right nasal cavity but nonnegotiable on left. So, probable diagnosis was depressed nasal bridge with probable left choanal atresia. She was sucking well with no respiratory distress.

With facial dysmorphism and warfarin intake till $3^{\text {rd }}$ trimester, suspicion of FWS was made clinically. Radiograph of chest and abdomen revealed multiple discrete punctate epiphyseal foci involving spine (bilateral paraspinally and overlyingvertebral bodymidportion) and bilateral proximal femoral and humeral epiphyses 
suggestive of epiphyseal stippled calcification (Figure 2, Figure 3). Visible femur and humerus showed normal length. The pattern was consistent with FWS.

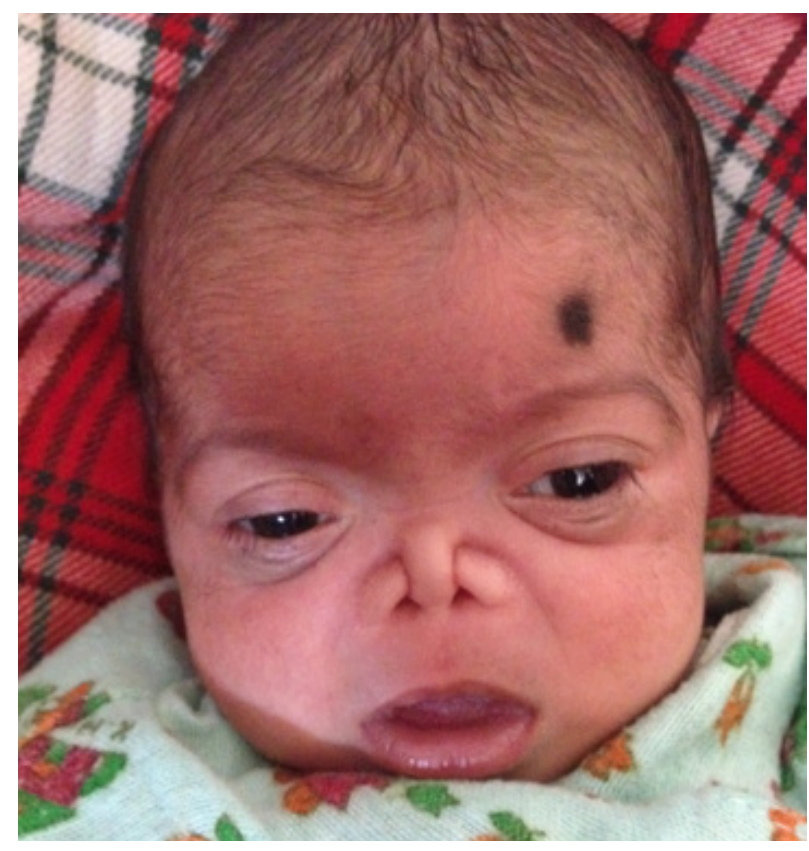

Figure 1. Photograph of infant demonstrating depressed nasal bridge and widely placed eyes

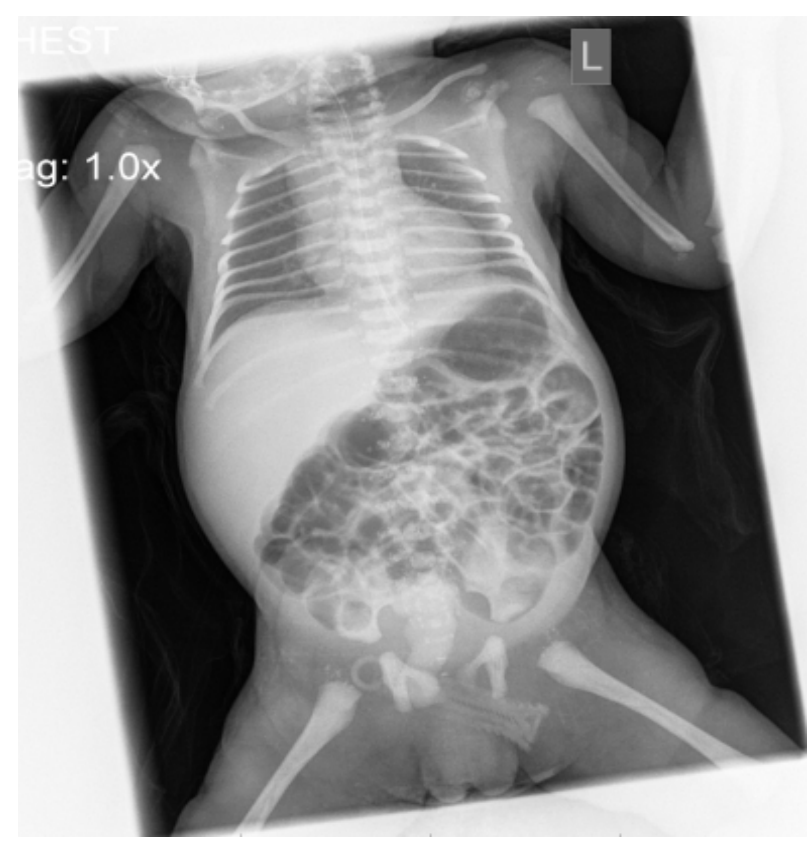

Figure 2. Radiograph demonstrating stippled epiphysis in proximal humerus and femoral epiphysis and spine epiphysis.

USG cranium was normal. She was awaiting ENT evaluation for probable left choanal atresia at one month of life.

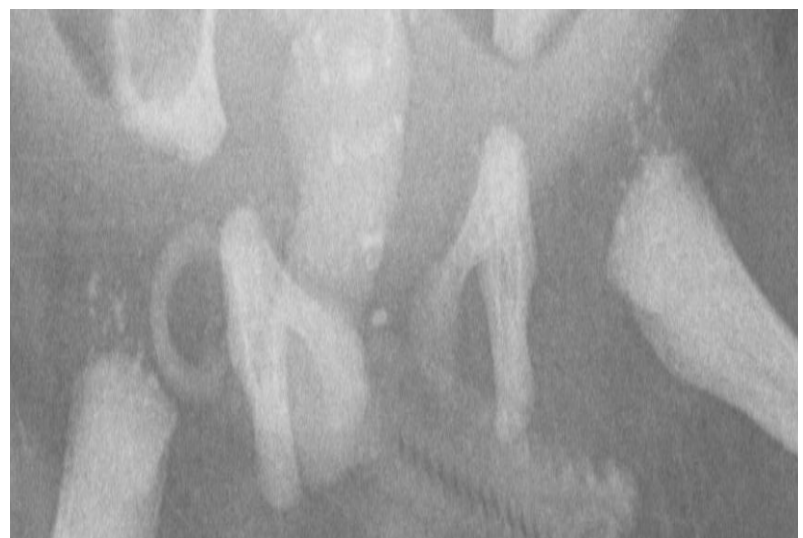

Figure 3. Radiograph demostrating stippled epiphysis of bilateral femoral epiphysis and sacral spine.

\section{DISCUSSION}

Epiphyseal stippling or chondrodysplasiapunctate (CDP) on itself does not constitute a diagnosis, but is a sign. ${ }^{1}$ It is seen in a range of pathologies -inherited bone dysplasia, maternal autoimmune illness, vitamin $K$ deficiency, warfarin fetopathy, inborn error of metabolism and rare syndromes. ${ }^{2}$ It is characterized by abnormal calcification in cartilaginous skeleton along with some extraosseous sites and by consistent facial dysmorphism phenotype with depressed nasal bridge. ${ }^{3}$ Spranger et $\mathrm{al}^{4}$ reported two types of CDP: milder, $X$-linked dominant Conradi-Hunermann syndrome with good prognosis, and severe, $\mathrm{X}$-linked recessive rhizomelic form with lethal outcome. Irving et al. ${ }^{3}$ divided CDP into three classes:chromosomal,associated with metabolic abnormalities and deranged vitamin $\mathrm{K}$ metabolism.

Warfarin therapy, maternal vitamin K deficiency, intestinal malabsorption, severe hyperemesis gravidarum which are associated with deranged vitamin $\mathrm{K}$ metabolism have been described to cause CDP. ${ }^{3,5,6}$ Exact etiopathogenesis of CDP related to vitamin $\mathrm{K}$ metabolism is unknown. Conradi-Hunermann syndrome CDP as a result of vitamin $\mathrm{K}$ dependent enzyme arylsufatase $\mathrm{E}$ deficiency is also included in this group. Features to distinguish lethal rhizomelic form from Conradi-Hunermann syndrome are presence of rhizomelia, absence of vertebral stippling, presence of extraosseous ossification, sparing of hands and feet and symmetry. ${ }^{7}$

The infant was diagnosed as FWS based on history of maternal warfarin intake at therapeutic dosage till 35 weeks, typical facial dysmorphism and generalized stippled epiphyses involving femora, humeri and vertebrae (Conradi-Hunermann syndrome CDP phenotype). Other differentials are perioxisomal 
disorders, maternal SLE and chromosomal disorders.

Oral warfarin is anticoagulant of choice in prosthetic heart valve patients. It can readily cross the placenta leading to clinically significant levels in fetus resulting in warfarin embryopathy. ${ }^{8}$

Skeletal abnormalities following exposure to coumadin derivatives in the first trimester were the first manifestations of FWS to be recognized. Hence, initial FWS diagnostic criteria was: coumadin derivative exposure during the first trimester and the presence of either nasal hypoplasia or stippled epiphyseal calcification. ${ }^{5}$ Other clinical manifestations include frontal bossing, short neck, low birth weight, short limbs, polydactyly and respiratory difficulty secondary to choanal atresia. Second and third trimester exposure is linked to debilitating CNS malformation and intracranial hemorrhage.

Epiphyseal stippling results in only few problems as is incorporated into the calcified epiphyses. However scoliosis may develop on stippled vertebrae. ${ }^{9}$ Nasal hypoplasia and nasal bridge depression may lead to flattened and upturned nasal appearance. A deep groove between alaenasi and nose tip, probably secondary to undergrown cartilage, is often present. Therefore, nares and nasal passages may be small, leading to neonatal respiratory distress secondary to upper airway obstruction in half of the patients. Fortunately, the small nasal passages will enlarge with age. ${ }^{9}$

Anticoagulation of pregnancy with prosthetic heart valve is problematic and is still a matter of debate. The fact that recommendations by American Heart Association, American College of Chest Physicians and European Society of Cardiology vary about the anticoagulant management in pregnancy clearly indicates the dilemma. ${ }^{10-12}$ Various regimens have been recommended that range from complete exclusion of warfarin, substitution of warfarin by heparin during 6-12 weeks to almost near complete use of warfarin with near term substitution by heparin. However these recommendations are futile and are based on only case reports, case series, small cohort studies and questionnaires. The ultimate choice of anticoagulants for pregnant patients with mechanical heart valves is also determined by the economic and resource limitations. The choice and risks of anticoagulation should be discussed with the patient before and immediately after diagnosis of pregnancy. ${ }^{12,13}$

\section{CONCLUSIONS}

Warfarin during pregnancy is associated with embryopathy and FWS with classical bony and facial abnormalities. $\mathrm{CDP}$ is a sign and not disease. A patient with radiographic features of CDP needs detailed evaluation to rule out deranged vitamin $\mathrm{K}$ metabolism and other differential diagnoses.

\section{REFERENCES}

1. Poznanski AK. Punctate epiphyses: a radiological sign not a disease. Pediatr Radiol. 1994;24(6):418-24. [PubMed]

2. Schulz SW, Bober M, Johnson C, Braverman N, Jimenez SA. Maternal mixed connective tissue disease and offspring with chondrodysplasia punctata. Semin Arthritis Rheum. 2010;39;410-6. [PubMed]

3. Irving MD, Chitty LS, Mansour S, Hall CM. Chondrodysplasia punctata: a clinical diagnostic and radiological review. Clin Dysmorphol. 2008;17(4):229-41. [PubMed]

4. Spranger JW, Langer LO, Wiedeman HR. Bone dysplasias: an atlas of constitutional disorders of skeletal development. Philadelphia:W.B. Saunders; 1974.

5. Hall JG, Pauli RM, Wilson KM. Maternal and fetal sequelae of anticoagulation during pregnancy. Am J Med. 1980;68(1):122-40. [PubMed]

6. Brunetti-Pierri N, Hunter JV, Boerkoel CF. Gray matter heterotopias and brachytelephalangic chondrodysplasia punctata: a complication of hyperemesis gravidarum induced vitamin K deficiency? Am J Med Genet A. 2007;143A(2):200-4. [PubMed]

7. Panda A, Gamanagatti S, Jana M, Gupta AK. Skeletal dysplasias: a radiographic approach and review of common non-lethal skeletal dysplasias. World J Radiol. 2014;6(10):808-25. [PubMed]

8. Walfisch A, Koren G. The "warfarin window" in pregnancy: the importance of half-life. J Obstet Gynaecol Can. 2010;32(10):988-9. [PubMed]

9. Hou JW. Fetal warfarin syndrome. Chang Gung Med J. 2004;27(9):691-5. [PubMed]

10. Castellano JM, Narayan RL, Vaishnava P, Fuster V. Anticoagulation during pregnancy in patients with a prosthetic heart valve. Nat Rev Cardiol. 2012;9(7):415-24. [PubMed]

11. Guyatt GH, Akl EA, Crowther M, Gutterman DD, Schuünemann HJ. Executive summary: antithrombotic therapy and prevention of thrombosis, $9^{\text {th }}$ ed: Ameri- 
can College of Chest Physicians evidence-based clinical practice guidelines. Chest. 2012;141(suppl 2):7S-47S. [PubMed]

12. McLintock C. Anticoagulant choices in pregnant women with mechanical heart valves: balancing maternal and fetal risks - the difference the dose makes. Thromb Res.
2013;131 (Supplement 1):S8-10. [PubMed]

13. Chan WS, Anand S, Ginsberg JS. Anticoagulation of pregnant women with mechanical heart valves: a systematic review of the literature. Arch Intern Med. 2000;160(2):1916. [PubMed] 